\title{
METÁFORA, CONTEXTO E INCORPORAÇÃO NA RETÓRICA NEOPENTECOSTAL
}

\author{
METAPHOR, CONTEXT, AND EMBEDMENT IN \\ NEO-PENTECOSTAL RHETORIC
}

\begin{abstract}
Erik Fernando Miletta Martins
Universidade Federal do Rio Grande do Norte, Natal, Rio Grande do Norte, Brasil erikmiletta@gmail.com

Marcela Costa De Souza

Universidade Federal do Rio Grande do Norte, Natal, Rio Grande do Norte, Brasil

marceladesouza27@gmail.com
\end{abstract}

Resumo: Segundo Hunt (2000), as igrejas neopentecostais têm como característica central a capacidade de adaptação a contextos espaço-temporais variados. Isto posto, neste artigo trabalhamos com a hipótese de que transformações ocorridas no contexto sociopolítico nacional ao longo de uma década afetou a produção textual-interativa presente em sermões neopentecostais. O foco de nossa atenção está no emprego de metáforas, fundamentais ao sucesso da retórica neopentecostal (MARTINS, 2011; 2015, 2017). Para alcançar os resultados, analisamos a relação entre a conceptualização metafórica da categoria INVESTIMENTO e a incorporação (HANKS, 2008) de mudanças no habitus (BOURDIEU, 1996) do público-alvo em dois cultos, um ministrado no ano de 2007 e outro no ano de 2017. Os resultados apontam que, em 2007, a categoria INVESTIMENTO é conceptualizada em termos determinísticos de um percurso. Já em 2017, o locutor conceituou INVESTIMENTO em termos de uma escolha. Ao longo da análise apontamos possíveis motivações para esta diferença e, em nossa conclusão, sugerimos que na retórica neopentecostal a incorporação do contexto sociopolítico ao discurso produziu efeitos na construção de estratégias argumentativas direcionadas à adesão às práticas financeiras, como os dízimos e as ofertas.

Palavras-chave: Metáfora; Contexto; Retórica; Igrejas Neopentecostais

Abstract: According to Hunt (2000), Neo-Pentecostal churches have as main characteristic the capacity for adaptation to different spatial-temporal contexts. Thus, in this article we work with the hypothesis that contextual sociopolitic transformations in the country, which occurs in the course of a decade, changed the textual-interactive production of Neo-Pentecostal sermons. We focus our attention on the use of metaphors, fundamental to the success of Neo-Pentecostal rhetoric (MARTINS, 2011, 2015, 2017). To achieve the outcomes, we analyzed the relationship between the metaphorical conceptualization of the category INVESTIMENT and the embedment (HANKS, 2008) of habitus (BOURDIEU, 1996) changes of the target public in two cults, one was ministered in 2007 and the other in 2017. The results show that in 2007 the speaker conceptualized INVESTIMENT in terms of a path. Already in 2017, the speaker conceptualized INVESTIMENT in terms of a choice. In our analyses we point out possible motivations to explain this difference and, in our conclusions, we suggest that in NeoPentecostal rhetoric embedment of the socio-political context into discourse produced effects 
in the argumentative strategies to persuade the audience to adhere to financial practices, such as the tithe and the offers.

Keywords: Metaphor; Context; Rhetoric; Neo-Pentecostal Churches

\section{DA RELAÇÃO ENTRE METÁFORA E CONTEXTO: UM POSICIONAMENTO SOCIOCOGNITIVO}

Dentre as várias possibilidades, dentro da Linguística, de pensar a relação entre língua e cognição, este trabalho insere-se na agenda dos estudos sociocognitivos da linguagem (MORATO, 2017; KOCH; CUNHA-LIMA, 2004; SALOMÃO, 1999; TOMASELLO, 1999 inter al.). Em particular, adere-se ao estudo desta relação através do crivo da Linguística Textual, significando, entre outras coisas, trabalhar com os seguintes postulados:

a) Centralidade da questão da referência como organizadora da relação entre linguagem e cognição. Afinal, é na forma como damos a conhecer o mundo através da linguagem que podemos encontrar problemas epistemológicos comuns (MARTINS, 2017) aos estudos sobre ambos os temas.

b) Não há referência linguística sem algum processo interacional de "negociação da realidade" (GOFFMAN, 1974). Esta, portanto, é instável e constituída como processo intersubjetivo e social, sendo transmitida entre gerações através do "efeito catraca" (TOMASELLO, 1999), dado seu caráter historicamente situado ${ }^{1}$.

c) O texto, objeto central da Linguística Textual, lugar de construção e negociação da referência, é uma "forma de cognição social que permite ao homem organizar cognitivamente o mundo" (KOCH, 2002, p. 157) e um evento comunicativo, no qual "convergem ações cognitivas, discursivas e sociais" (BEAUGRANDE, 1997, p. 26). Estamos diante, portanto, de uma unidade mínima de sentido, organizada por uma inescapável solidariedade entre processos linguísticos e cognitivos na construção - e não apenas no processamento - textual (MORATO, 2017).

d) A linguagem, e o texto, estão longe de ser mero reflexo de processos cognitivos, como a categorização, a memória, a sensório-motricidade ou até mesmo a metáfora ${ }^{2}$, dada a inter-relação funcional, mutuamente constitutiva, entre linguagem e cognição (MARTINS, 2011) reivindicada na agenda dos estudos sociocognitivos da linguagem.

A partir destes postulados, nosso posicionamento sobre a questão da metáfora, tal como operada junto à Linguística Cognitiva como percurso para pensar a relação entre língua e cognição, adquire contornos específicos, dando à noção de contexto maior força descritiva e analítica. Embora esta já se apresente em diversos estudos sobre a metáfora, não raro é operacionalizada com grande ênfase ao co-texto, ou entorno verbal ou, ainda, "contexto situacional” (KÖVECSES, 2015). Apesar de importantes, estas duas dimensões são insuficientes para dar conta do processo de construção de sentido textual via metáfora.

Uma das consequências mais imediatas desse posicionamento implica mutualidade e instabilidade na relação entre domínios analógicos da experiência, havendo predominância de influência do domínio fonte sobre o domínio alvo. Essa percepção é caudatária da premissa

\footnotetext{
1 "Símbolos linguísticos incorporam uma miríade de maneiras de construir o mundo intersubjetivamente que foram acumuladas em uma cultura através do tempo histórico" (TOMASELLO, 1999, p. 96. Tradução nossa)

${ }^{2}$ Não custa lembrar que em alguns desenvolvimentos da Linguística Cognitiva, em especial em sua origem junto ao trabalho seminal de Lakoff e Johnson (1980), admite-se uma hierarquia rígida na interface entre processos cognitivos (anteriores, primários) e linguísticos (posteriores, secundários).
} 
sobre a instabilidade referencial, quando trata da noção de discurso: "o discurso constrói os 'objetos' a que faz remissão, ao mesmo tempo que é tributário dessa construção" (KOCH, 2002, p. 30). Também a noção de contexto opera de modo dinâmico junto ao discurso: "as práticas discursivas são configuradas e ajudam a configurar os contextos em vários níveis" (idem, p. 174). Por isso, entendemos que o domínio-alvo também contribui, em menor escala, para a organização conceptual do domínio-fonte, salientando apenas aspectos deste.

\section{METÁFORA, TEXTO E CONTEXTO: A ORGANIZAÇÃO CONCEPTUAL DA RETÓRICA NEOPENTECOSTAL}

É lugar-comum nos estudos sobre o neopentecostalismo apontar a capacidade dos líderes destas igrejas em realizar uma exploração simbólica (MARIANO, 2008) dos problemas cotidianos de boa parte da população urbana brasileira, em especial dos habitantes das periferias. Um de seus pilares, a Teologia da Prosperidade, tem por crença central a ideia de que o "cristão verdadeiro" - completamente alinhado à visão de mundo e dedicado às práticas neopentecostais, como o dízimo, as ofertas e o missionarismo - tem por direito reivindicar uma vida saudável e economicamente abundante. O projeto retórico do neopentecostalismo concerne à difusão universal destas crenças e tem na metáfora um de seus principais instrumentos de persuasão às práticas que o alimentam, como os dízimos e as ofertas.

Um aspecto fundamental para o estudo das metáforas em contextos religiosos está na percepção de que as religiões monoteístas são organizadas em torno de algumas metáforas básicas, um "conglomerado ou rede em que certas metáforas recorrentes tanto organizam metáforas subsidiárias quanto difundem novas" (TRACY, 1992 apud MARTINS, 2011, p. 95). Uma noção que nos ajuda a detectar estas metáforas básicas é a de Nicho Metafórico. Inspirada na Teoria Conceptual da Metáfora (LAKOFF; JOHNSON, 1980), esta noção oferece a vantagem de localizar a atuação de proposições metafóricas em textos e discursos (e não apenas em sentenças $a d h o c)$, uma vez que é definida enquanto:

um grupo de expressões metafóricas, inter-relacionadas, que podem ser vistas como desdobramentos cognitivos e discursivos de uma proposição metafórica superordenada normalmente presente (ou inferida) no próprio co-texto (VEREZA, 2007, p. 496).

Há de se notar, entretanto, que nosso posicionamento é levemente diferente do encontrado no trabalho acima referido. Além de derivarmos os nichos por meio de conjuntos de textos tematicamente semelhantes, entendemos ser fundamental salientar o papel do contexto na organização destes. Assim, em estudos prévios (MARTINS, 2011, 2015), notamos a atuação de dois grandes nichos metafóricos na organização da retórica neopentecostal: PROSPERIDADE É CONSUMO e FÉ É INVESTIMENTO.

Se os domínios-alvo das metáforas também contribuem na organização dos domíniosfonte, como mencionado, no caso de FÉ É INVESTIMENTO, temos que o elemento do domínio-alvo, FÉ, é mapeado em termos de uma experiência mais concreta presente no domínio-fonte, INVESTIMENTO. Não por acaso um traço típico da fé, a incondicionalidade, aparece na conceptualização de investimento.

Deve-se observar, entretanto, que mesmo as experiências com práticas de investimento, isto é, de aplicação de recursos com objetivo de retorno envolvendo cálculo de risco, não podem ser qualificadas como comuns ou acessíveis ao público-alvo destas igrejas. Via de regra composto por pessoas em situação de pobreza, desprovidas de acesso a bens simbólicos, pouco amparadas por políticas públicas e dissociadas de redes relacionais de apoio, 
dado serem oriundas dos grandes êxodos das décadas de 1970-80. Por isso, a sorte da retórica neopentecostal também depende do emprego de metáforas conceptuais capazes de organizar a experiência do investimento.

\section{SOBRE O MÉTODO: DIMENSÕES DO CONTEXTO E A PRESENÇA DA METÁFORA}

Os dados a serem ora analisados fazem parte de um longo projeto de pesquisa sobre a expansão e consolidação do neopentecostalismo no Brasil. Por uma questão de escopo, trabalharemos apenas com trechos extraídos de cultos da Igreja Universal do Reino de Deus (IURD). A escolha por essa dá-se em função de sua proeminência nacional tanto no quadro religioso e cultural quanto no quadro político. Enquanto precursora do neopentecostalismo no país e modelo de sucesso para igrejas semelhantes, a IURD qualifica-se como um protótipo para a categoria (MARTINS, 2015).

A análise a ser empreendida baseia-se em uma comparação entre metáforas associadas à prática do investimento extraídas de dois cultos televisionados e ministrados pelo líder, o Bispo Edir Macedo. O primeiro foi ministrado, registrado e transcrito ${ }^{3}$ no ano 2007, enquanto o segundo no ano de 2017. Esta diferença de dez anos parece ser suficiente para enxergarmos se as transformações no cenário sociopolítico brasileiro provocaram alguma alteração na configuração textual e argumentativa de metáforas associadas à experiência do investimento. Os trechos aqui analisados, portanto, competem a esse recorte temático. A opção por estes cultos, diante do corpus geral de nossas pesquisas, ampara-se na similaridade temática entre ambos.

Como noção de contexto, apoiamo-nos na proposta de Hanks (2008), para quem este é composto de duas dimensões inseparáveis: a emergência e a incorporação. A emergência concerne ao curso da interação e organiza o contexto em três níveis: situação, cenário e campo semiótico. Já a incorporação concerne aos traços de cada um dos níveis que vão sendo incorporados para a formação e, assim, para a construção de um novo contexto.

O culto neopentecostal não se reduz ao nível da situação - referente à presença mútua de interlocutores (HANKS, 2008), mas a um nível mais estruturado, o cenário. Neste nível, o culto aparece enquanto evento comunicativo organizado por camadas dispostas na situação, envolvendo atos socialmente identificáveis, expectativas, compreensão entre as partes, e, principalmente, a instauração de um sistema de relevância mútua. Quando ao cenário é atribuído significado na forma de signos, instaura-se um nível mais estruturado, o campo semiótico, composto por um campo demonstrativo (o "aqui-agora-eu") e um campo simbólico (uso de itens lexicais).

As expectativas implicadas na projeção do pathos - relativa aos valores atribuídos ao auditório pelo orador (MEYER, 2007) - são ancoradas na percepção que o locutor tem do groundedness (idem), isto é, do assentamento do cenário em uma dimensão socio-histórica. Somente assim o orador irá enquadrar o discurso e estabelecer um sistema de relevância, de forma a determinar quais as estratégias formais serão ou não utilizadas, averiguando eficácia destas. Dentre tais estratégias, destacam-se as metáforas, emergentes no campo simbólico (HANKS, 2008).

O campo semiótico, assim como todos os outros níveis de contexto, não existe em um vazio social. Por isso, o autor empresta de Bourdieu a noção de campo social, relativa ao espaço delimitado de posições e de tomadas de posição por meio das quais valores circulam. No caso

\footnotetext{
${ }^{3}$ Empregamos normas adaptadas do Projeto NURC.
} 
do campo social religioso do culto há posições e posturas determinadas: o orador detém o poder unilateral de fala, e o auditório, composto por fiéis, tende a interagir apenas por meio de reações à fala do orador.

\section{ANÁLISE DE DADOS}

\subsection{CULTO 1 (2007) - INVESTIMENTO É UM PERCURSO}

Em relação ao primeiro culto, o campo demonstrativo assume a seguinte configuração: o aqui é o culto televisionado a partir de um dos principais templos da IURD; o agora, seria o ano de 2007; e o eu, seria o líder da igreja, o bispo Edir Macedo. Para fazer a projeção do pathos às expectativas do orador foi incorporado o groundedness (HANKS, 2008) do "agora": momento em que políticas públicas de combate à miséria ${ }^{4}$ e de estímulo ao consumo ${ }^{5}$ estavam em fase de implementação. Por isso, nessa projeção podemos notar a referência a elementos de abundância de elementos básicos como traços de uma prosperidade almejada pelo auditório:

1- É a vontade de Deus que você... que todos nós tenhamos uma vida de qualidade... uma vida com saúde... uma boa família... você comer abundantemente... comer com fartura... amém... Ter fartura na sua casa - "ah... tô com vontade de comer isso... num tem problema... tem aqui... ah quero comer aquilo... num tem problema.

Considerando que os enunciados, em suas dimensões simbólica e indicial, tanto refletem como transformam o contexto (HANKS, 2008), é necessário olharmos não só para a metáfora de INVESTIMENTO em si, como também para as outras metáforas incorporadas e capazes de organizá-la. Vejamos, no extrato abaixo, como orador lida com o provérbio "se a vida te der um limão, faça uma limonada":

2- Eu aprendi que do limão a gente deve fazer uma limonada... eu aprendi que... quanto mais fundo é o poço que a gente está... mais forte é o grito... e para o alto... e para $o$ alto... e é ai que a gente tem a experiência com Deus [...]. dificilmente as pessoas têm experiência com Deus... quando tudo vai bem”.

É interessante notar como o provérbio é preenchido por outra metáfora bastante corrente, o "fundo do poço". Embora esse provérbio tenda a ser aplicado a situações de superação, a metáfora o recategoriza ${ }^{6}$ através de um paralelismo sintático parafrástico, ensejando um efeito de sentido no qual quanto mais difícil está a situação de uma pessoa, maior a necessidade de recursos a serem aplicados. Vale destacar também a presença de uma metáfora orientacional bastante comum nas culturas ocidentais: MAIS É PARA CIMA. Não por acaso, na sequência, vê-se como a fé (conceito abstrato) é entendida em termos de "grito" (conceito concreto) a ser direcionado para o alto, lugar ocupado por Deus.

Essa projeção do pathos vai ganhando maior relevância na sequência do dado, quando o orador começa a oferecer contornos específicos à metáfora do fundo do poço, colocando-a como domínio-alvo de termos como: "filho doente", "ficar com fome", "ficar desalojado",

\footnotetext{
${ }^{4}$ Programas como o Fome Zero e o Bolsa Família.

${ }^{5}$ Valorização real do salário mínimo, diminuição das taxas de juros e criação de linhas de crédito para pessoas de baixa renda.

${ }^{6}$ Um estudo específico sobre as formas, funções e modos específicos de processamento das recategorizações metafóricas dessas anáforas nominais pode ser encontrado em Martins (2017).
} 
"morando na rua", "desgraças" e "mazelas". Esses índices metafóricos emergem no discurso do orador para sugerir que tais adversidades não são culpa de Deus, mas do Diabo. Neste momento, portanto, incorpora-se ao texto a crença na Batalha Espiritual ${ }^{7}$.

Depois de elucidar o auditório sobre a raiz das adversidades, o orador mostra a solução incorporando ao texto a crença no Segundo Batismo. Nesse trecho, podemos perceber como o investimento é entendido em termos de um percurso em direção a Deus e, assim, à prosperidade. No extrato abaixo, seguir este percurso depende apenas de uma escolha individual, cabendo ao indivíduo optar por estar perto de Deus ou do Diabo:

3- Quando nos voltamos pra Ele... nós abrimos um espaço pra Ele interferir na nossa vida... Agora se nós não tomarmos essa atitude... de forma nenhuma Ele vai agir em nós... de forma nenhuma... de maneira nenhuma... Ele sempre vai esperar uma manifestação da nossa fé... (...) quando a pessoa então manifesta a sua fé em Deus... no Deus de Abrão... no Deus de Isaac... no Deus de Israel... (...) ela fica livre do que os homens dizem... ela se agarra ao Deus vivo... ao Deus verdadeiro... e ai a vida dela passa a ter uma qualidade porque ela começa... ela aprende a viver em comunhão com Deus... ela passa a viver é...em relacionamento com Deus... [...] A sua fé é a ponte entre você e Deus... quando você usa essa fé... quando você atravessa essa fé... ou essa ponte... você tem Deus à disposição.

Após mostrar o motivo do problema e o caminho para a solução, o orador preocupase em qualificar o que o fiel irá encontrar ao final do percurso. Não por acaso, há retomada do item "qualidade", associado à fartura de recursos básicos.

Nessa passagem, o orador busca elucidar ao fiel quanto à importância de buscar investir na relação com o sagrado, para ocupar um lugar privilegiado na hierarquia, sendo o lugar mais baixo o fundo do poço (próximo ao Diabo) e o lugar mais alto perto de Deus, lugar de direito do verdadeiro cristão. O relacionamento com Deus, assim, é o resultado do investimento através da aplicação do recurso da fé, fortemente associada aos dízimos e ofertas, metaforizada nesse trecho em termos de uma ponte entre a pessoa e Deus.

Em outra passagem, o orador introduz a metáfora do projeto, por meio da qual induz o auditório a compreender o sucesso do investimento - metaforizado enquanto um edifício suntuoso - depende apenas de uma decisão individual. Ou seja, para atingir o Segundo Batismo, o fiel deve "colocar em prática o projeto que está no papel". Esta metáfora é fundamental ao orador para associar a aplicação de recursos às práticas dizimistas e ofertantes:

4- Então primeiro você faz um projeto... num é isso? Num é um projeto? É ou não é? Então primeiro tem um projeto... aquele projeto feito pelos engenheiros... os arquitetos... aquele projeto tá no papel. Uma vez colocando em prática surge um edifício como esse. Os grandes edifícios começam no papel...

Diante destes extratos, há maior clareza sobre como o orador transita entre dimensões relevantes do contexto macro, projetando ao auditório pessoas, em sua maioria, desacreditadas, com poucos recursos para aplicação da fé, devido às adversidades oriundas da escassez de recursos materiais. O sistema de relevância organiza-se em direção à persuasão sobre a Teologia da Prosperidade, na qual o investimento, sob a forma de entrega incondicional, é peça

\footnotetext{
${ }^{7}$ A classificação dos tipos de comportamento guia-se pela lógica mais ampla da crença da Batalha Espiritual entre Deus e o Diabo pela humanidade, capaz de oferecer qualidades a vencedores e vencidos; ao mesmo tempo, a crença no Segundo Batismo pavimenta a possibilidade de conversão dos vencidos em vencedores.
} 
central. Não por acaso, na sequência do culto, o orador aponta qual o retorno do investimento: um relacionamento com Deus e uma vida próspera. A garantia sobre esse investimento é retratada junto à experiência pessoal do orador, cujo resultado é o templo onde ocorre o culto.

O efeito de sentido gerado por cada metáfora emergente no discurso do orador depende do efeito de sentido gerado no contexto pela metáfora anterior a ela, havendo incorporação de uma metáfora a outra. Dessa forma, evidencia-se a retroalimentação entre texto e contexto (HANKS, 2008). Assim, é devido à incorporação de outras metáforas que, nesse culto, podemos notar a presença do nicho INVESTIMENTO É UM PERCURSO, isto é, o investimento aqui é apresentado para o auditório como o único caminho à desejada prosperidade.

\subsection{CULTO 2 (2017) - INVESTIMENTO É UMA ESCOLHA}

Já no culto de 2017, o cenário, relacionado ao campo demonstrativo (HANKS, 2008), é o Templo de Salomão, atual sede da IURD e um símbolo de poder e status ${ }^{8}$. O "eu” continua sendo o líder da igreja, Edir Macedo, politicamente mais forte com a eleição de diversos membros do PRB nas eleições municipais de $2016^{9}$.

O agora é o ano de 2017, cujo contexto macro sofreu alterações nos campos político, econômico e, consequentemente, social. Embora não cheguem a reordenar o que há de mais elementar aos objetivos da retórica neopentecostal, tais mudanças reconfiguram estratégias de persuasão, como a projeção do pathos (MEYER, 2007).

Após a crise econômica internacional de 2008, o país passa por um boom econômico, chegando ao status de "emergente", dado o pico de crescimento (7,5\%) em 2010. Esse resultado foi atingido, em parte, devido a políticas federais de incentivo ao consumo interno, aumentando o potencial aquisitivo de grupos de baixa renda e garantindo-lhes maior chance de usufruto de produtos antes inalcançáveis, como aparelhos eletrônicos (PINHEIRO-MACHADO; SCALCO, 2018) e bens duráveis, como automóveis e imóveis. Esta reconfiguração implica novas disposições e práticas, novos modos de ser, de se comportar e de enxergar o mundo de acordo com a posição ocupada no espaço social - elementos configuradores de um habitus (BOURDIEU, 1996). O groundedness do agora reflete novos tipos de projeção do habitus do público-alvo, havendo relevância desse elemento do cenário incorporado ao campo semiótico emergente. Vejamos como ocorre essa nova forma de projeção do pathos:

5- Você pode ter o título que tiver... a honra que tiver, o mundo pode colocá-lo LÁ em cima, no pináculo do templo... mas se não tiver... no altar... para ser santificado, para ser... consagrado, para ser aceito você num/ não vale nada... nada... nada...

Diferente do que observamos no culto de 2007, neste nota-se a presença de itens lexicais como "título" e "honra", associados a um capital simbólico referente a elementos de distinção social mais bem difundidos neste período ${ }^{10}$. Embora "o mundo", uma metáfora para a sociedade secular, possa colocar essa pessoa em uma posição de superioridade, valendo-se de uma recorrente dicotomia no universo cristão entre pessoas mundanas e sagradas, estes bens podem não ter valor algum perante o sagrado.

\footnotetext{
${ }^{8}$ A inauguração do templo, no ano de 2014, contou com a presença de diversos líderes de Estado à época, como a presidenta Dilma Rousseff, o governador do estado de São Paulo, Geraldo Alckmim e o prefeito da cidade de São Paulo, Fernando Haddad.

${ }^{9}$ Destaca-se a eleição do Bispo da IURD e sobrinho de Edir Macedo, Marcelo Crivella, para a prefeitura da cidade do Rio de Janeiro.

${ }^{10}$ Vale notar como o emprego destes itens parece estar atrelado à expansão do sistema de educação superior, seja público, seja privado.
} 
Já a metáfora "pináculo do templo" visa reforçar essa pretensa imagem de superioridade, por meio da qual o orador acessa um elemento indexicalizado ao cenário, concreto e imediato da experiência dos participantes dessa interação - o ponto mais alto do templo - de modo a facilitar a compreensão de um elemento abstrato da experiência: a organização social e posições de prestígio. Aqui, como no culto de 2007, vê-se a exploração da metáfora conceptual MAIS É PARA CIMA. A analogia, entretanto, tem por função desqualificar a prosperidade mundana, indicando sua legitimidade apenas quando é alcançada pela via religiosa. Não por acaso, na sequência do dado emerge a metonímia "altar", lugar de sacralização dos recursos materiais mundanos investidos e retornados por Deus. Esse recurso é bastante comum na retórica da IURD, tendo função primordial na persuasão sobre os dízimos e ofertas (MARTINS, 2011): a única prosperidade material moralmente aceitável é fruto de um investimento na relação com Deus.

Como se vê, se o contexto sócio-econômico de 2007 pressionava o orador a apontar a relação com Deus como imprescindível para superação da escassez de recursos básicos. Já em 2017 essa relação é reconfigurada, dado o aumento do poder aquisitivo geral do público-alvo. Afinal, se antes a prosperidade, fruto do investimento, era conceptualizada por meio do consumo e acesso a itens básicos, em 2017 o fruto do investimento deve ser a garantia da legitimidade religiosa não só destes itens, mas de bens duráveis e simbólicos. Esta diferença é fundamental para entendermos outra metáfora recorrente neste culto, a do sacrifício. Vejamos o extrato abaixo:

6- Eu decido... eu entrego a minha vida... eu sacrifico... ainda que eu tenha que negar toda a minha carne... a minha vontade... [...] ainda que venha gemer por isso eu... eu assumo essa posição... quando eu assumo essa posição de seguir Jesus sacrifiquei mesmo a minha vida... virei as costas pro mundo... morri pro mundo... então o Senhor Jesus vem ao meu encontro na pessoa do Espírito Santo e faz-me nascer de novo.

Podemos identificar neste extrato uma série de expressões indicadoras da categoria SACRIFÍCIO associada a uma noção de investimento: "entrego minha vida" enquanto metáfora para entrega completa; "negar toda a minha carne", "gemer", enquanto metáforas associadas ao abandono das coisas mundanas e, por consequência, como elementos que fortalecem o argumento de entrega dos bens materiais; "virei as costas" e "morri para o mundo" como metáforas associadas à privação do consumo, ao desapego de bens materiais, em prol do uso destes para o investimento na relação com Deus.

Ademais podemos ver qual seria o resultado deste caminho doloroso. Através da incorporação da crença no Segundo Batismo, o orador procura persuadir o auditório in loco ${ }^{11}$ sobre a importância do desapego material para a legitimação religiosa dos bens materiais e simbólicos. Aqui, a lógica do risco do investimento é colocada em proporção: quanto menos bens, menor o apego e maior a chance de sucesso no empreendimento divino:

7- Então as pessoas mais pobres... mais necessitadas... [...] mais sofridas têm mais... probabilidade de serem transformadas da natureza... é terrena para a natureza celestial porque elas não têm nada a perder então elas estão prontas pra sacrificar o resto que tem... "Toma aqui minha vida"

\footnotetext{
${ }^{11}$ Lembrando que o acesso aos cultos no Templo de Salomão ministrados por Macedo são disputados e de difícil acesso.
} 
O orador, atento ao resultado do esforço individual - explicitado sob a lógica do consumo secular e do acúmulo de bens - procura dissuadir o público-alvo do medo de arriscar e da dúvida sobre o resultado final. A metáfora do sacrifício, então, ganha força ao indicar que a prosperidade chancelada por Deus só ocorre mediante entrega incondicional dos bens materiais. Vê-se, aqui, como o maior poder aquisitivo da população tem um lado positivo, pela chance de entrada de recursos vultuosos, e um lado negativo, dado o maior apego material ao resultado do trabalho e investimento seculares.

Neste culto, tanto como no de 2007, podemos notar, por um lado, a preservação do nicho metafórico FÉ É INVESTIMENTO. Mas, ao contrário daquele, há uma diferente organização associada à aplicação dos recursos da fé - traduzidos sob a forma de dízimos e ofertas. As metáforas incorporadas sugerem a necessidade de uma argumentação menos determinística, por meio da qual Macedo procura apontar diversos caminhos como resultado do investimento. $\mathrm{O}$ recurso à crença na Batalha Espiritual, embora menos explícito, emerge como indicador; manter-se com natureza mundana, apegado aos bens, é manter-se próximo ao Diabo; optar pela natureza celestial é aproximar-se de Deus. A partir desses arrazoados, parece prudente apontar como nicho metafórico deste culto que INVESTIMENTO É UMA ESCOLHA.

\section{CONSIDERAÇÕES FINAIS}

A partir deste trabalho, pudemos trazer mais elementos para reforçar a hipótese cunhada em Martins (2015) de que o contexto sociopolítico nacional organiza a produção textual e retórica dos sermões neopentecostais. Em nossa análise comparativa, as diferentes metáforas ligadas ao conceito de investimento parecem caudatárias da incorporação de elementos do contexto sócio-econômico à projeção do pathos. Recorrer à escassez de recursos em 2007 cria um sistema de relevância interpessoal produtivo aos propósitos da retórica neopentecostal, assim como parece produtivo ao orador recorrer à possibilidade de escolhas em 2017.

Como visto, em 2007 encontramos o nicho INVESTIMENTO É UM PERCURSO e, em 2017, encontramos INVESTIMENTO É UMA ESCOLHA. Essa diferença parece estar intimamente ligada às transformações no habitus do público-alvo destas igrejas. Assim, embora possamos alegar que os pilares da retórica neopentecostal, como a Teologia da Prosperidade e os respectivos nichos metafóricos, a crença na Batalha Espiritual e no Segundo Batismo, permanecem intactos - bem como os objetivos missionários de expansão destes pilares não só em nível nacional, mas mundial - houve clara necessidade de reorganização das estratégias argumentativas de persuasão, em especial na direção das práticas de investimento nos objetivos expansionistas, alimentados por dízimos e ofertas.

\section{REFERÊNCIAS}

BEAUGRANDE, Robert De. New Foundations for a science of text and discourse. 1997. Disponível em: http://www.beaugrande.com/new_foundations_for_a_science.htm.

BOURDIEU, Pierre. Razões práticas: sobre a teoria da ação. 3.ed. Campinas: Papirus, 1996.

GOFFMAN, Erving. Frame analysis. Harper \& Row, New York. 1974. 
HANKS, Willian. O que é contexto. In: BENTES, A. et al (Orgs.) Língua como prática social: das relações entre língua, sociedade e cultura a partir de Bourdieu e Bakhtin. São Paulo: Cortez, 2008 [1999].

HUNT, Stephen. 'Winning Ways': Globalisation and the Impact of the Health and Wealth Gospel. Journal of Contemporary Religion, vol. 15, no. 3, 2000.

KOCH, Ingedore Grünfeld Villaça. Desvendando os segredos do texto. Cortez, São Paulo. 2002.

$\mathrm{KOCH}$, Ingedore Villaça; CUNHA LIMA, Maria Luiza. Do Cognitivismo ao Sociocognitivismo. In: BENTES, Anna Christina; MUSSALIN, Fernanda. (Org.). Introdução a Linguística - Fundamentos Epistemológicos. vol. 3. 1 ed. São Paulo, 2004, v. 3, p. 251300 .

KÖVECSES, Zoltan. Where metaphors come from: reconsidering context in metaphor. New York: OUP, 2015.

LAKOFF, George.; JOHNSON, Mark. Metaphors We Live By. Chicago: The University of Chicago Press. 1980.

MARIANO, Ricardo. Crescimento pentecostal no Brasil: fatores internos. REVER, São Paulo, Dezembro, 2008, p. 68-95.

MARTINS, Erik Fernando Miletta. O percurso sócio-cognitivo das recategorizações metafóricas: Construção de sentidos na retórica neopentecostal. 2011. 215 p. Dissertação (Mestrado em Linguística) - Instituto de Estudos da Linguagem, Universidade Estadual de Campinas, Campinas, São Paulo, 2011.

MARTINS, Erik Fernando Milleta. Frames neoliberais na retórica neopentecostal: aspectos referenciais e sociocognitivos. 2015. 233 p. Tese (Doutorado em Linguística) - Instituto de Estudos da Linguagem, Universidade Estadual de Campinas, Campinas, São Paulo, 2015.

MARTINS, Erik Fernando Miletta. Sobre a singularidade das formas correferenciais metafóricas. INVESTIGAÇÕES (ONLINE), v. 30, 2017, pp. 101-129.

MEYER, Michel. A retórica. Trad. Lineide Mosca. Ed. Ática. 2007.

MORATO, Edwiges Maria. Linguística Textual e Cognição. In: SOUZA, Edson Rosa; PENHAVEL, Eduardo; CINTRA, Marcos Rogério. (Org.). Linguística Textual: Interfaces e delimitações. 1.ed. São Paulo: Cortez, 2017, v. 1, pp. 394-430.

PINHEIRO-MACHADO, Rosana; SCALCO, Lucia Mury. Da esperança ao ódio: a juventude periférica bolsonarista. In: SOLANO, Esther (org.). O ódio como política. 1. ed. São Paulo: Boitempo, 2018, pp. 53-63.

SALOMÃO, Maria Margarida Martins. A questão da construção do sentido e a revisão da agenda dos estudos da linguagem. Veredas, v.3, n.1, p. 61-79, jan/jun.1999. 
TOMASELLO, Michael. Cultural origins of human cognition. Cambridge/Massachusetts: Harvard University Press. 1999.

VEREZA, Solange. Metáfora e argumentação: uma perspectiva discursiva. Linguagem em (dis)curso. v. 7, n. 3, p. 487-506, 2007.

Recebido em: 01 de fevereiro de 2020 Aceito em: 13 de abril de 2020

Publicado em Maio de 2020 